\title{
Is Lenke Rule About Selective Thoracic Fusion Applicable for Younger Adult Idiopathic Scoliosis Under 40 Years of Age: Comparison With Adolescent Patients
}

\section{Honglei Yi}

PLA General Hospital of Southern Theatre Command: People's Liberation Army General Hospital of Southern Theatre Command

Hu Chen

PLA General Hospital of Southern Theatre Command: People's Liberation Army General Hospital of Southern Theatre Command

\section{Xinhui Wang}

PLA General Hospital of Southern Theatre Command: People's Liberation Army General Hospital of

Southern Theatre Command

\section{Wei Zhang}

Changhai Hospital

\section{Hong Xia ( $\nabla$ gzxiahong2@126.com )}

PLA General Hospital of Southern Theatre Command: People's Liberation Army General Hospital of Southern Theatre Command https://orcid.org/0000-0003-3651-8410

\section{Research article}

Keywords: younger adult idiopathic scoliosis, adolescent idiopathic scoliosis, surgical outcome冈selective thoracic fusion,complications

Posted Date: January 27th, 2021

DOl: https://doi.org/10.21203/rs.3.rs-154106/v1

License: (c) (1) This work is licensed under a Creative Commons Attribution 4.0 International License. Read Full License 


\section{Abstract}

Background To evaluate the surgical outcome of younger adult idiopathic scoliosis patients (YAdIS) with selective thoracic fusion by comparing with adolescent idiopathic scoliosis (AIS).

Methods Seventy-two idiopathic scoliosis patients (36 adults and 36 adolescents) treated by posterioronly all-pedicle screw technique at the same institution were retrospective reviewed and matched by curve pattern and curve magnitude. Radiographic parameters were evaluated preoperatively, postoperatively and at final follow-up. Operating time, blood loss, transfusion and complications were noted. Clinical outcome was assessed by Scoliosis Research Society-22 questionnaire (SRS-22).

Results The major thoracic curves in YAdIS group and AIS group were $56.3^{\circ} \pm 9.7^{\circ}, 53.3^{\circ} \pm 10.1^{\circ}$ and corrected to $17.2^{\circ} \pm 7.3^{\circ}, 14.9^{\circ} \pm 7.5^{\circ}$ respectively without significant difference of correction rate $(69.3 \%$ vs. $72.0 \%)$. For the lumbar curve, Cobb angles in two groups were $35.6^{\circ} \pm 10.1^{\circ}$ and $31.4 \pm 9.2^{\circ}$ preoperatively, and was spontaneously corrected to $18.5^{\circ} \pm 9.0^{\circ}$ and $12.6^{\circ} \pm 8.2^{\circ}$. Correction rates were 48.0\% and 59.8\% (Pख0.05). Coronal vertebra alignments (CVA) in YAdIS group were $20.6 \pm 9.7 \mathrm{~mm}$ before surgery and $16.8 \pm 7.9 \mathrm{~mm}$ after surgery (P®0.05), while CVA in the AIS group was $17.8 \pm 10.5 \mathrm{~mm}$ preoperatively and decreased to $9.7 \pm 8.3 \mathrm{~mm}$ postoperatively $(\mathrm{P} \bigotimes 0.05)$. However, sagittal parameters showed significant improvements in thoracic kyphosis in both groups (P区0.05). Complication rates were $13.9 \%$ vs. $5.6 \%$ without significant difference. Preoperative SRS score was worse in the YAdIS group than the AIS group. However, there were no significant differences between the final SRS score.

Conclusions YAdIS patients gained similar correction of major thoracic curve as AIS patients, although the curve were stiffer.However,more extensive release technique needed to be done which was associated with longer operation time hospital stay. YAdIS had more complications,though this difference was not statistically significant. Patients with lower SRS score in YAdIS can also be treated very well with selective thoracic fusion surgery.

\section{Background}

Adult idiopathic scoliosis (AdIS) is special subcategory of spine deformity that does not develop de novo in patients over 18 years old, which may be due to the worsening of untreated childhood idiopathic scoliosis. The prevalence rate among adults under 45 years old is about $2 \%-4 \%[1,2]$.

The treatment of AdIS involves both surgical and non-surgical options. Surgical treatment is frequently necessary when curves progress, body pain and disability happens. However, several reports have shown that there are age-associated differences for radiographic parameters and disability in AdIS patients. It is suggested that pain and disability were main factors that influenced the treatment modality for older patients with adult scoliosis. However, for younger patients, operative treatment was driven by increased frontal plane deformity [3-5]. The diversity of AdIS population included in previous studies was treated as a whole without making a distinction between younger adult and older adult patients, which may 
result in potentially confounding[6-8].Thus, it's necessary for us to discuss the radiographic and clinical characters of younger adult idiopathic scoliosis (YAdIS) under age of 40 separately.

As we know, for the adolescent idiopathic scoliosis (AIS), selective thoracic fusion (STF) is always proved to be successful when the criteria below were met. Lenke et al suggested that 2 or 3 ratios of thoracic to lumbar curves (Cobb angle ratio > 1.2, AVT ratio > 1.2, AVR ratio > 1.0) should be fulfilled to obtain successful outcomes after STF. In addition, curves not meeting the ratio criteria or those with lumbar curves $>60^{\circ}$, Nash-Moe's rotation grade $>2.5$, or AVT $>4.0 \mathrm{~cm}$ should not be treated as STF [10-11]. However, for the younger adult idiopathic scoliosis patients (YAdIS), how to choose the best surgical strategy is still unclear. Unlike AIS patients, curve would be stiffer after skeletally mature in YAdIS, which may need longer fusion segments and more extensive release. Thus, the complication rate may be higher and the recovery would be slower, because age was proved to be associated with increased risk of hemorrhage, infection, and reoperation [9].

Up to now, there are few information about the surgical outcome of younger adult idiopathic scoliosis patients(under age of 40) (YAdIS). We propose a retrospective matched cohort study to compare YAdIS with AIS treated with STF strategy to demonstrate whether this Lenke rule is applicable for the YAdIS patients.

\section{Methods}

After approving by the institution review board (IRB) of the hospital, participants or, where participants are children, a parent or guardian, who signed the Informed Consent Form were taken into this retrospective study. From Jan 2008 to Jul 2012, consecutive population of 36 adolescents and 36 younger adults with single or double thoracic scoliosis were retrospective reviewed and matched by magnitude and pattern of the curve. Major curve ranged from 45-75 degrees. All patients met the criteria of STF (T/L cobb angle ratio $>1.2)$ stated by Lenke. All patients were treated with posterior-only pedicle screw technique by the same group of surgeons.

In the YAdIS Group, the average age was $29.1 \pm 2.5$ years. 5 cases were male and 31 cases were female, with an average follow-up of $32.7 \pm 5.3$ months (24-36 months).According to the SRS classification system[12], 25 cases were single thoracic scoliosis and 11 cases were double thoracic scoliosis. The indication of surgery for these patients were curve progression and cosmetic problem. Meanwhile, some of them suffered from back pain. Most of these patients chose to delay surgery because they were worried about the effect on children's spinal growth, patients' studies, daily activities and psychological states.[13]. Unfortunately, these untreated spinal deformities still progressed as patients aging.

Patients included in Group AIS were from 10 to 18 years old with average age of $13.8 \pm 2.8$ years. Based on Lenke classification system[14], 28 patients were typed Lenke $1(21$ of $1 A, 5$ of $1 B, 2$ of $1 C)$ and 8 patients were typed Lenke 2( 5 of $2 \mathrm{~A}, 2$ of $2 \mathrm{~B}, 1$ of $2 \mathrm{C}$ ). 


\section{Surgical Procedure}

For the AIS Group, all patients were placed in a prone position after general anesthesia. After a posterior midline incision was made, subperiosteal paraspinal muscle was dissected to expose the posterior bone structure. Pedicle screws were inserted into the fusion segments bilaterally with free hand technique. Fusion strategy was performed in accordance with the principle of Lenke classification. All the structural major and minor curves were fused while non-structural compensatory curves were not included. For 10 patients with fixed deformity, multiple Ponte osteotomies [15] were used to attain correction via a posterior approach. Curve correction was achieved using the direct vertebral derotation maneuver, followed by slight convex compression and concave distraction. Decortication of the posterior elements was performed after the correction, and poster-lateral fusion was done with allograft, autograft, followed by wound closure gradually and drainage retained.

For the YAdIS group, the same procedure was done. As patients in our research didn't have radicular symptoms of lower extremity, nerve root and spinal canal decompression were not performed. Multisegmental Ponte osteotomies [15] were done in 20 patients because of stiffer curve in younger adults.

Somatosensory-evoked potentials and MEP were routinely assessed for intraoperative monitoring of spinal cord function. Self-transfusion was used. All patients in the study were operated by the same group of surgeons. The average OR time, fusion levels, intraoperative blood loss, blood transfusion, hospital days were recorded.

\section{Radiographic And Clinical Evaluation}

All patients had pre- and post-operative standing AP and lateral radiographs. Coronal curves, T5-T12 and L1-sacrum sagittal Cobb were measured. We defined the proximal junctional angle as the caudal endplate of the upper instrumented vertebrae (UIV) to the cephalad endplate of the vertebrae two superadjacent levels above the UIV. Coronal balance (i.e., coronal vertical alignment, CVA) was measured as the distance between $\mathrm{C7}$ plumb line and the mid-sacral line (imbalance: $>2 \mathrm{~cm}$ ). Overall radiographic sagittal balance (i.e., sagittal vertical alignment, SVA) was measured as the distance between C7 plumb line and the posterior-superior aspect of S1[16]. A positive value indicated that the $\mathrm{C7}$ plumb line fell in front of the posterior superior aspect of $\mathrm{S} 1$, whereas a negative value indicated that this line fell in back of this point. Preoperative fulcrum lateral bending X-ray films were used to evaluate the flexibility of the curve[17].

Outcome analysis was performed using the Scoliosis Research Society-22. SRS questionnaires were available for $100 \%$ of patients. Radiographic measurements were performed by independent surgeons for twice. Whole spine MRI scan were used to check any inter spinal cord abnormity and to evaluate degeneration of thoracic or lumbar intervertebral disc, stenosis of central spinal canal, lateral recess or foramen. 


\section{Statistical Analysis}

All data were analyzed by SPSS version 21.0 statistical analysis software (SPSS Inc., Chicago, USA). Continuous variables were presented as mean standard deviation, and ordinal variables as median (interquartile range). Paired t-test was used to compare all the variables between the two groups. Fisher's exact test was used to test for significance of categorical variables. All statistical assessments were 2sided and evaluated at the 0.05 level of significance.

\section{Results}

Table 1 summarized the preoperative characteristics and surgical variables for both Groups. Fusion levels in YaDIS group (10.47 \pm 1.84$)$ were a little longer than that in AIS group (10.28 \pm 1.92$)$ without significant difference. OR time and length of hospital stay were longer in YaDIS group than AIS group, while estimated blood loss, transfusion were not statistically different. Major thoracic Cobb in YAdIS group was $56.3^{\circ} \pm 9.7^{\circ}$ at standing AP films preoperatively, and corrected to $29.1^{\circ} \pm 11.5^{\circ}$ at fulcrum bending image. Comparatively, preoperative major thoracic curve cobbs in AIS Group were $53.3 \pm 10.1$ at standing AP film and $21.6^{\circ} \pm 9.2^{\circ}$ at fulcrum bending film. The thoracic flexibility of YaDIS group and AIS group was $48.3 \%$ and $59.5 \%$ respectively with significant difference (Pख0.05). Likewise, the lumbar flexibility in YaDIS group and AIS group was $55.4 \%$ and $67.3 \%$, which were also significantly different (P凶0.05). Major thoracic cobb in YAdIS Group and AIS Group decreased to $17.2^{\circ} \pm 7.3^{\circ}$ and $14.9^{\circ} \pm 7.5^{\circ}$ after surgery with surgical correction rate $69.4 \%$ and $72.0 \%$, respectively without significant difference (P凶0.05). For the lumbar curve, Cobb angle in two groups was $35.6^{\circ} \pm 10.1,31.4 \pm 9.2^{\circ}$ preoperatively, and corrected spontaneously to $18.5^{\circ} \pm 9.0^{\circ}, 12.6^{\circ} \pm 8.2^{\circ}$, which showed the correction rates of $48.0 \%, 59.8 \%$ with significant differences (Pख0.05). At last follow-up, major thoracic curve and lumbar curve were not statistically different from that of postop. (Pख0.05). (Table 2) .CVA(as assessed by absolute value) in YAdIS group were $20.6 \pm 9.7 \mathrm{~mm}$ before surgery and $16.8 \pm 7.9 \mathrm{~mm}$ after surgery without significant difference (P区0.05), while CVA in AIS group was $17.8 \pm 10.5 \mathrm{~mm}$ preoperatively and decreased to $9.7 \pm 8.3 \mathrm{~mm}$ postoperatively with significant difference (P凶0.05). This showed patients in YAdIS group gained less postoperative improvement of CVA than AIS group (Pख0.05). Coronal balance in two groups at last followup got well maintained. (Table 2). Preoperatively, thoracic kyphotic angles were $24.0^{\circ} \pm 8.4^{\circ}, 26.2^{\circ} \pm 8.5^{\circ}$ in YAdIS and AIS group respectively. Postoperative thoracic kyphosis in both groups were $31.5^{\circ} \pm 7.5^{\circ}$ and $32.5^{\circ} \pm 7.6^{\circ}$ which showed significant improvement $(\mathrm{P} \otimes 0.05)$ comparing with preoperative measurements. The thoracic kyphosis in two groups can still be well maintained at last follow-up. Global sagittal balance did not significantly change after surgery in either group (P凶0.05). (Table 2) (Fig. 1,2) 
Table 1

preoperative characteristics and surgical variables for the YAdIS and AIS Group

\begin{tabular}{|llll|}
\hline & YAdIS(36) & AlS(36) & Pvalue \\
\hline Operating age $($ Y) & $29.1 \pm 2.5$ & $13.8 \pm 2.8$ & $<0.001$ \\
\hline Major thoracic curve cobb $\left(^{\circ}\right)$ & $56.3 \pm 9.7$ & $53.3 \pm 10.1$ & $>0.05$ \\
\hline Coronal lumbar curve cobb $\left(^{\circ}\right)$ & $35.6 \pm 10.1$ & $31.4 \pm 9.2$ & $>0.05$ \\
\hline Thoracic kyphosis $\left(^{\circ}\right)$ & $24.0 \pm 8.4$ & $26.2 \pm 8.5$ & $>0.05$ \\
\hline Lumbar lordosis $\left({ }^{\circ}\right)$ & $46.8 \pm 11.0$ & $49.2 \pm 9.3$ & $>0.05$ \\
\hline CVA (mm) & $20.6 \pm 9.7$ & $17.8 \pm 10.5$ & $>0.05$ \\
\hline SVA (mm) & $25.6 \pm 13.1$ & $22.3 \pm 14.4$ & $>0.05$ \\
\hline Major thoracic flexibility $(\%)$ & $48.3 \pm 10.4$ & $59.5 \pm 11.5$ & $<0.05$ \\
\hline Lumbar flexibility $(\%)$ & $55.4 \pm 9.3$ & $67.3 \pm 11.2$ & $<0.05$ \\
\hline Esetimated blood loss $(\mathrm{ml})$ & $852.8 \pm 167.9$ & $813.1 \pm 142.0$ & 0.07 \\
\hline Transfusion $(\mathrm{ml})$ & $566.7 \pm 205.6$ & $538.4 \pm 191.3$ & 0.36 \\
\hline OR time (h) & $3.4 \pm 0.7$ & $3.1 \pm 0.5$ & 0.007 \\
\hline Fusion levels & $10.47 \pm 1.84$ & $10.28 \pm 1.92$ & $>0.05$ \\
\hline Hospital days $(\mathrm{d})$ & $11.6 \pm 1.7$ & $9.9 \pm 1.4$ & $<0.001$ \\
\hline Follow-up(month) & $32.7 \pm 5.3(26 \sim 48)$ & $34.4 \pm 6.3(24 \sim 50)$ & $>0.05$ \\
\hline
\end{tabular}


Table 2

Preoperative, postoperative and final follow-up radiographic measurements in two groups

\begin{tabular}{|c|c|c|c|c|c|c|}
\hline & \multicolumn{3}{|c|}{ YAdIS Group } & \multicolumn{3}{|c|}{ AIS Group } \\
\hline & preop & postop & FFU & preop & postop & FFU \\
\hline $\begin{array}{l}\text { Major thoracic curve } \\
\text { cobb }\left({ }^{\circ}\right)\end{array}$ & $\begin{array}{l}56.3 \pm \\
9.7\end{array}$ & $\begin{array}{l}17.2 \pm \\
7.3^{\star}\end{array}$ & $\begin{array}{l}18.5 \pm \\
7.5\end{array}$ & $\begin{array}{l}53.3 \pm \\
10.1\end{array}$ & $\begin{array}{l}14.9 \pm \\
7.5^{*}\end{array}$ & $\begin{array}{l}16.1 \pm \\
8.6\end{array}$ \\
\hline Lumbar curve cobb $\left(^{\circ}\right)$ & $\begin{array}{l}35.6 \pm \\
10.1\end{array}$ & $\begin{array}{l}18.5 \pm \\
9.0^{\star}\end{array}$ & $\begin{array}{l}19.8 \pm \\
8.3\end{array}$ & $\begin{array}{l}31.4 \pm \\
9.2\end{array}$ & $\begin{array}{l}12.6 \pm \\
8.2^{\star}\end{array}$ & $\begin{array}{l}14.8 \pm \\
9.1\end{array}$ \\
\hline Thoracic kyphosis $\left(^{\circ}\right)$ & $\begin{array}{l}24.0 \pm \\
8.4\end{array}$ & $\begin{array}{l}31.5 \pm \\
7.5^{\star}\end{array}$ & $\begin{array}{l}30.5 \pm \\
8.1\end{array}$ & $\begin{array}{l}26.2 \pm \\
8.5\end{array}$ & $\begin{array}{l}32.5 \pm \\
7.6^{\star}\end{array}$ & $\begin{array}{l}33.6 \pm \\
5.5\end{array}$ \\
\hline Lumbar lordosis $\left({ }^{\circ}\right)$ & $\begin{array}{l}46.8 \pm \\
11.0\end{array}$ & $\begin{array}{l}50.1 \pm \\
9.1\end{array}$ & $\begin{array}{l}49.7 \pm \\
8.6\end{array}$ & $\begin{array}{l}49.2 \pm \\
9.3\end{array}$ & $\begin{array}{l}50.8 \pm \\
7.9\end{array}$ & $\begin{array}{l}50.3 \pm \\
12.5\end{array}$ \\
\hline $\mathrm{CVA}(\mathrm{mm})$ & $\begin{array}{l}20.6 \pm \\
9.7\end{array}$ & $\begin{array}{l}16.8 \pm \\
7.9\end{array}$ & $\begin{array}{l}17.5 \pm \\
8.3\end{array}$ & $\begin{array}{l}17.8 \pm \\
10.5\end{array}$ & $9.7 \pm 8.3^{*}$ & $\begin{array}{l}11.5 \pm \\
9.7\end{array}$ \\
\hline SVA (mm) & $\begin{array}{l}25.6 \pm \\
13.1\end{array}$ & $\begin{array}{l}22.3 \pm \\
13.5\end{array}$ & $\begin{array}{l}23.4 \pm \\
11.6\end{array}$ & $\begin{array}{l}22.3 \pm \\
14.4\end{array}$ & $\begin{array}{l}18.5 \pm \\
12.6\end{array}$ & $\begin{array}{l}20.1 \pm \\
10.7\end{array}$ \\
\hline
\end{tabular}

In both groups, no patient had neurologic deficit, constructs failure or pseudarthrosis. One patient in YAdIS group experienced deep wound infection that needed debridement. Nevertheless, 4 patients experienced postoperative coronal imbalance at the most recent follow-up in YAdIS Group, while 2 patients showed postoperative coronal decompensation in the AIS group. No cases of sagittal decompensation were observed in either group. The complication rate in YAdIS group was higher than AIS group (13.9\% vs $5.6 \%)$, but no significant difference was found $(P=0.49)$.

\section{Clinical Outcomes}

The mean follow-up duration for the YAdIS group was 32.7 months while it was 34.4 months for AIS group without significant difference. In the YAdIS group, the mean preoperative SRS score was 3.3, and the mean postoperative SRS score was $4.1(\mathrm{P}<0.001)$. In AIS group, the mean preoperative SRS score was 3.7, and the mean postoperative SRS score was $4.2(P<0.001)$. The preoperative SRS in YAdIS group were worse than AIS group $(p<0.05)$. However, there were no significant differences between two groups in SRS at last follow-up (Table 3). 
Table 3

Comparison of the SRS-22 scores before and after Surgery

\begin{tabular}{|lccc|}
\hline & YAdIS Group & AIS Group & $P$ value \\
\hline SRS-22 & & & \\
\hline Preoperative & $3.3 \pm 0.5$ & $3.7 \pm 0.4$ & $<0.05$ \\
\hline Postoperative & $4.1 \pm 0.3^{*}$ & $4.2 \pm 0.3^{*}$ & $>0.05$ \\
\hline *preop VS postop $\mathrm{p}<0.05$ & & \\
\hline
\end{tabular}

\section{Discussion}

Idiopathic scoliosis cases among adults actually began during adolescence. For younger adult idiopathic scoliosis, they seldom complain symptoms relevant with spinal or lateral recess stenosis, but care more about the appearance, which is very different from older patients who focus more on the functional ability. Only one paper discussed the relationship between the sagittal plane change and clinical improvement in AdIS older than 40 years of age [18. However, surgical outcome of YAdIS may be different from older ones or overall adult patients. This study tried to demonstrate the surgical outcome of YAdIS under age of 40 by comparing with AIS, in which issue very few studies have been done.

This retrospective matched cohort study included 72 cases of younger adult and adolescent idiopathic thoracic scoliosis operated with STF according to Lenke rules mentioned in AIS [9-11]. Correction rates of major thoracic curve in two groups were $69.3 \%$ and $72.0 \%$ respectively without significant difference, though statistical differences were shown in fulcrum flexibility of major thoracic curve ( $48.5 \%$ vs $59.5 \%$ ). The results are accordant with other studies. Peelle reported the thoracic correction rate of $62 \%$ using selective thoracic fusion for adult idiopathic scoliosis[8]. Our previous study demonstrated the correction rate was from $52 \%-55 \%$ depending on the different age group of AdIS[7]. The reason for a little bit lower correction rate in that study may due to more severe curves with an average Cobb of 72 degrees. The other reason may be that more patients in YAdIS group (20/36) had been done posterior Ponte osteotomies to increase flexibility [19]. Even for the severe and rigid adult idiopathic scoliosis, Ponte osteotomies were effective to gain satisfactory correction despite major complications [20].This was also associated with a little longer operation time and blood loss in YAdIS group.

Correction rates of lumbar curves response to selective thoracic fusion in two groups were $48.0 \%$ and $59.8 \%$ and both suggested good spontaneous correction of lumbar curves. As was reported in the study of selective thoracic fusion by Peelle[8], there was $50 \%$ spontaneous correction of lumbar curves, which was comparable to $48 \%$ in our YAdIS group. However, the spontaneous correction rate of lumbar curve in YAdIS group was significantly less than AIS group (59.8\%), which may be due to different flexibility of lumbar curve in two groups (55.4\% vs $67.3 \%$ ). The importance of the lumbar curve flexibility is advocated in the selective thoracic fusion for AIS population. The ratio of flexibility of thoracic versus lumbar curves 
has also been deemed predictive of successful thoracic fusions[21]. For adult patients, there is not a "cutoff" value for lumbar curve flexibility, as adults with presumably stiffer curves may possess less intrinsic elasticity for correction. However, some lumbar curves in adults may mimic the response of adolescent curves, whereas others may exhibit considerably more rigidity.

Furthermore, different lumbar curve spontaneous correction rate may lead to the different incidence of coronal decompensation in YAdIS group and AIS group (11.1\% vs $5.5 \%)$. The incidence of coronal decompensation has been reported to range from $10-40 \%$ by hooks or hybrid constructs, while $5-16 \%$ by pedicle screw constructs[22-24].It's postulated that excessive thoracic curve correction and the relative inability of the lumbar curve to accommodate the correction of the thoracic were factors in postoperative trunk decompensation[24]. Although this conclusion was made by Suk in AIS patients, this theory may also be suitable for the selective thoracic fusion for the treatment of YAdIS patients too. Carefully evaluating the flexibility of thoracic/lumbar curve and predicting the ability of the minor curve spontaneous correction preoperatively is very important to minimize decompensation.

Sagittal plane alignment was also evaluated in these two groups. We did not find thoracic kyphosis reduced postoperatively. Suk et al.[25] also reported good correction of preoperative hypokyphosis (from $9^{\circ}$ to $27^{\circ}$ ) in their study. This result was contrary to several other independent studies which noted an average loss of between $10^{\circ}$ and $12^{\circ}$ in thoracic kyphosis in pedicle screws treatment of AIS[22, 26, 27]. Better sagittal thoracic hypokyphosis correction in the present study may be due to sparse pedicle screws instead of all pedicle screws. Furthemore, Ponte osteotomy helps to release the posterior elements and may contribute to the restore of sagittal alignment [18]. The clinical improvement potential for sagittal lordotic change provided by Ponte osteotomies has been reported to be in the range of 9.3 to 10.78 per level. $[19,28]$ Restoring of normal thoracic kyphosis is of great importance for maintaining lumbar lordosis and preventing sagittal imbalance with aging especially for adult scoliosis [29]. Sagittal parameters have been proved to be strongly correlated with health-related quality of life and positive sagittal balance has been considered the most reliable predictor of clinical symptoms in operated adult scoliosis patients.

In this study, statistically significant improvement in SRS scores from preoperative to postoperative was seen in both groups. Although SRS score before surgery was worse in YAdIS group than AIS group, the health-related quality of life outcome was almost the same at the final follow-up.

\section{Limitation}

The limitations of the study are its retrospective nature, short-term follow-up and the small number of patients in this series.

\section{Conclusion}


YAdIS patients gained similar correction of major thoracic curve as AIS patients by selective thoracic fusion although the curve was stiffer. However, more extensive release technique needed which was associated with longer operation time. YAdIS had more complications, though this difference was not statistically significant. SRS scores for YAdIS were lower preoperatively but not different in postoperative improvement. This result suggested that YAdIS can also be treated very well with selective thoracic fusion based on Lenke rule used for AIS.

\section{Abbreviations}

younger adult idiopathic scoliosis patients, YAdIS; adolescent idiopathic scoliosis, AIS; Scoliosis Research Society-22 questionnaire, SRS-22; Coronal vertebra alignments, CVA; Adult idiopathic scoliosis, AdIS; health-related quality of life, HRQOL; institution review board, IRB; upper instrumented vertebrae, UIV; sagittal vertical alignment, SVA.

\section{Declarations}

\section{Ethics approval and consent to participate}

This case report had approved by the Ethics Committee of General Hospital of Southern Theater Command of PLA. Written informed consent about operative techniques and to the data-use agreement was obtained from all patients before surgery.

\section{Consent for publication}

Written informed consent for participation and publication in the study was obtained from participants.

\section{Availability of data and materials}

The datasets used and/or analysed during the current study are available from the corresponding author on reasonable request.

\section{Competing interests}

The authors declare no conflict of interest.

\section{Funding}

This research was supported by the National Natural Science Foundation of China (81972080), the Science and Technology Planning Project of Guangdong Province (2017B030314139), the Natural Science Foundation of Guangdong Province (2015A030312004). The funding organizations had no role in the design and conduct of the study; collection, management, analysis, and interpretation of the data; preparation, review, or approval of the manuscript; and decision to submit the manuscript for publication.

\section{Authors' contributions}


$\mathrm{HY}$ and $\mathrm{HC}$ carried out the data and drafted the manuscript. All authors read and approved the final manuscript. HX revised it critically for important intellectual content. All authors read and approved the final manuscript.

\section{Acknowledgements}

None.

\section{References}

1. Angevine PD. Deutsch H(2008)Idiopathic scoliosis.Neurosurgery. 63:86-93.

2. Perennou D, Marcelli C, Herisson C, Simon L. Adult lumbar scoliosis. Epidemiologic aspects in a lowback pain population. Spine. 1994;19:123-8.

3. Bess S, Boachie-Adjei O, Burton D, Cunningham M, Shaffrey C, Shelokov A, Hostin R, Schwab F, Wood K, Akbarnia B, International Spine Study G. Pain and disability determine treatment modality for older patients with adult scoliosis, while deformity guides treatment for younger patients. Spine. 2009;34:2186-90. DOI 10.1097/BRS.0b013e3181b05146.

4. Glassman SD, Schwab FJ, Bridwell KH, Ondra SL, Berven S, Lenke LG. The selection of operative versus nonoperative treatment in patients with adult scoliosis. Spine. 2007;32:93-7. DOI 10.1097/01.brs.0000251022.18847.77.

5. Fu KM, Bess S, Shaffrey Cl, Smith JS, Lafage V, Schwab F, Burton DC, Akbarnia BA, Ames CP, Boachie-Adjei O, Deverin V, Hart RA, Hostin R, Klineberg E, Gupta M, Kebaish K, Mundis G, Mummaneni PV, International Spine Study G. Patients with adult spinal deformity treated operatively report greater baseline pain and disability than patients treated nonoperatively; however, deformities differ between age groups. Spine. 2014;39:1401-7. DOI 10.1097/BRS.0000000000000414.

6. Lonner BS, Ren Y, Bess S, et al. Surgery for the Adolescent Idiopathic Scoliosis Patients After Skeletal Maturity: Early Versus Late Surgery. Spine Deform. 2019;7(1):84-92.

7. Li M, Shen Y, Gao ZL, Fang XT, Xie Y, Wang CF, Zhao YC, Zhu XD. Surgical treatment of adult idiopathic scoliosis: long-term clinical radiographic outcomes. Orthopedics. 2011;34:180. DOI 10.3928/01477447-20110124-14.

8. Peelle MW, Boachie-Adjei O, Charles G, Kanazawa Y, Mesfin A. Lumbar curve response to selective thoracic fusion in adult idiopathic scoliosis. The spine journal: official journal of the North American Spine Society. 2008;8:897-903. DOI 10.1016/j.spinee.2007.11.010.

9. Verla T, Adogwa 0 , Toche $U$, et al. Impact of increasing age on outcomes of spinal fusion in adult idiopathic scoliosis. World Neurosurg. 2016;87:591-7.

10. Lenke LG, Edwards CC 2nd, Bridwell. KH(2003)The Lenke classification of adolescent idiopathic scoliosis: how it organizes curve patterns as a template to perform selective fusions of the spine.Spine. 28(20S):S199-207. 
11. Ishikawa M, Nishiyama M, Kamata M,et al(2019) Apr Selective Thoracic Fusion for King-Moe Type II/Lenke 1C Curve in Adolescent Idiopathic Scoliosis: A Comprehensive Review of Major Concerns. Spine Surg Relat Res 27;3(2).

12. Lowe T, Berven SH, Schwab FJ, Bridwell KH. The SRS classification for adult spinal deformity: building on the King/Moe and Lenke classification systems. Spine. 2006;31:119-25. DOI 10.1097/01.brs.0000232709.48446.

13. Pizones J, Martin-Buitrago MP, Sanchez PF, et al(2016)Untreated thoracic curve in adult idiopathic scoliosis: what are patients' concerns? SpineDeform. 4:439-445.

14. Lenke LG, Betz RR, Harms J, Bridwell KH, Clements DH, Lowe TG, Blanke K. Adolescent idiopathic scoliosis: a new classification to determine extent of spinal arthrodesis. The Journal of bone joint surgery American volume. 2001;83-A:1169-81.

15. Ponte A, Orlando G, Siccardi GL(2018)The True Ponte Osteotomy: By the One Who Developed It. Spine Deform 6 (1), 2-11.

16. Lenke LG, Bridwell KH, Baldus C, Blanke K, Schoenecker PL. Ability of Cotrel-Dubousset instrumentation to preserve distal lumbar motion segments in adolescent idiopathic scoliosis. $\mathrm{J}$ Spinal Disord. 1993;6:339-50.

17. Cheung KM, Natarajan D, Samartzis D, Wong YW, Cheung WY, Luk KD. Predictability of the fulcrum bending radiograph in scoliosis correction with alternate-level pedicle screw fixation. The Journal of bone joint surgery American volume. 2010;92:169-76. DOI 10.2106/JBJS.H.01831.

18. Sánchez-Mariscal F, Gomez-Rice A, Rodríguez-López T, et al. Preoperative and postoperative sagittal plane analysis in adult idiopathic scoliosis in patients older than 40 years of age. The Spine Journal. 2017;17:56-61.

19. Halanski MA, Cassidy JA. Do multilevel Ponte osteotomies in thoracic idiopathic scoliosis surgery improve curve correction and restore thoracic kyphosis? J Spinal Disord Tech. 2013;26:252-5.

20. One-Stage Posterior Multiple-Level Asymmetrical Ponte Osteotomies Versus Single-Level Posterior Vertebral Column Resection for Severe and Rigid Adult Idiopathic Scoliosis.A Minimum 2-Year Follow-up Comparative Study.Spine,2019, 44,: E1196-E1205.

21. Rose PS, Lenke LG, Bridwell KH, Mulconrey DS, Cronen GA, Buchowski JM, Schwend RM, Sides BA. Pedicle screw instrumentation for adult idiopathic scoliosis: an improvement over hook/hybrid fixation. Spine. 2009;34:852-7. DOI 10.1097/BRS.0b013e31818e5962. discussion 858.

22. Dobbs MB, Lenke LG, Kim YJ, Kamath G, Peelle MW, Bridwell KH. Selective posterior thoracic fusions for adolescent idiopathic scoliosis: comparison of hooks versus pedicle screws. Spine. 2006;31:2400-4. DOI 10.1097/01.brs.0000240212.31241.8e.

23. Yu B, Zhang JG, Qiu GX, Wang YP, Zhao Y, Shen JX, Zhao H, Yang XY. Posterior selective thoracic fusion in adolescent idiopathic scoliosis patients: a comparison of all pedicle screws versus hybrid instrumentation. Chinese medical sciences journal = Chung-kuo i hsueh k'o hsueh tsa chih /. Chinese Academy of Medical Sciences. 2009;24:30-5. 
24. Suk SI, Lee SM, Chung ER, Kim JH, Kim SS. Selective thoracic fusion with segmental pedicle screw fixation in the treatment of thoracic idiopathic scoliosis: more than 5-year follow-up. Spine. 2005;30:1602-9.

25. Suk SI, Lee CK, Kim WJ, Chung YJ, Park YB. Segmental pedicle screw fixation in the treatment of thoracic idiopathic scoliosis. Spine. 1995;20:1399-405.

26. Lehman RA Jr, Lenke LG, Keeler KA, Kim YJ, Buchowski JM, Cheh G, Kuhns CA, Bridwell KH. Operative treatment of adolescent idiopathic scoliosis with posterior pedicle screw-only constructs: minimum three-year follow-up of one hundred fourteen cases. Spine. 2008;33:1598-604. DOI 10.1097/BRS.0b013e318178872a.

27. Lowenstein JE, Matsumoto H, Vitale MG, Weidenbaum M, Gomez JA, Lee FY, Hyman JE, Roye DP Jr. Coronal and sagittal plane correction in adolescent idiopathic scoliosis: a comparison between all pedicle screw versus hybrid thoracic hook lumbar screw constructs. Spine. 2007;32:448-52. DOI 10.1097/01.brs.0000255030.78293.fd.

28. Cho KJ, Bridwell KH, Lenke LG, et al. Comparison of SmithPetersen versus pedicle subtraction osteotomy for the correction of fixed sagittal imbalance. Spine (Phila Pa 1976). 2005;30:2030-7.

29. Newton PO, Yaszay B, Upasani VV, et al. Preservation of thoracic kyphosis is critical to maintain lumbar lordosis in the surgical treatment of adolescent idiopathic scoliosis. Spine (Phila Pa 1976). 2010;35:1365-70.

\section{Figures}

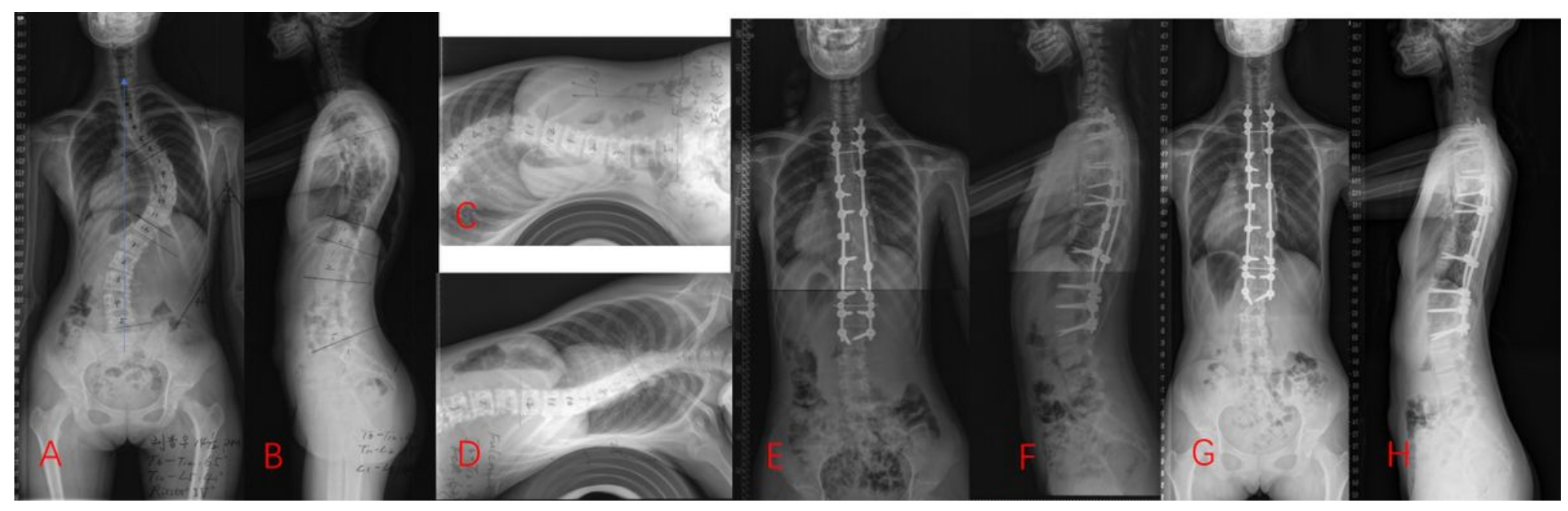

\section{Figure 1}

A 23+8-year-old female (Major thoracic curve, SRS system) was treated with posterior spinal fusion with pedicle screw instrumentation from T2 to L2. A, B: preoperatively, the major thoracic curve Cobb angle was 63 degrees. Lumbar curve was 40 degrees. Thoracic kyphosis (T5 to T12) was 32 degrees. SVA was $0 \mathrm{~mm}$ and CVA was $10 \mathrm{~mm}$. C, D: Fulcrum bending, thoracic curve Cobb angle decreased to 40 degrees with flexibility of $36.5 \%$. Lumbar curve cobb decreased to 16 degree with flexibility of $60 \%$. E, F: 
Postoperatively, the major thoracic Cobb angle was 22 degrees with correction rate of $65.1 \%$. Lumbar curve was 14 degrees. The thoracic kyphosis was 35 degrees. SVA was $-10 \mathrm{~mm} \mathrm{~mm}$ and CVA was $0 \mathrm{~mm}$. $\mathrm{G}, \mathrm{H}, 32$ months after surgery, correction maintained well.

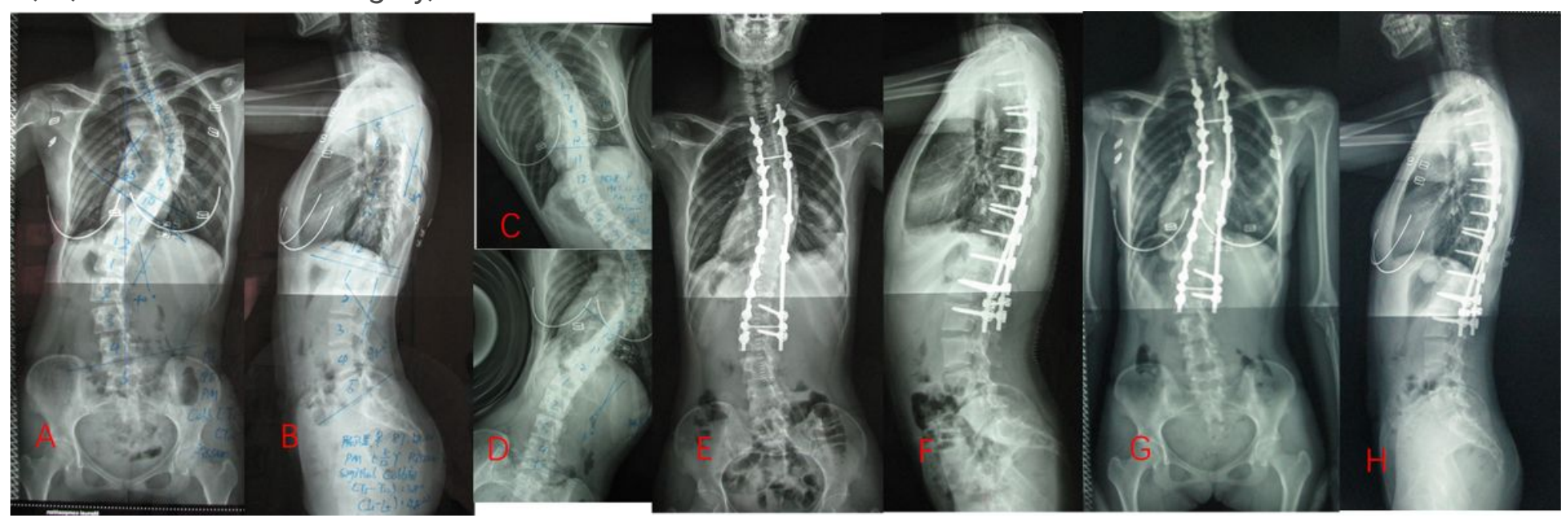

\section{Figure 2}

A 14+1-year-old boy (Lenke type 1AN) was treated with posterior spinal fusion with pedicle screw instrumentation from T2 to L2. A, B: Preoperatively, the major thoracic curve Cobb angle was 65 degrees. Lumbar curve was 40 degrees. Thoracic kyphosis (T5 to T12) was 40 degrees. Both SVA and CVA were 0 $\mathrm{mm}$. C, D: Fulcrum bending, thoracic curve Cobb angle decreased to 25 degrees with flexibility of $61.5 \%$. Lumbar curve decreased to 10 degrees with flexibility of $84.6 \% \mathrm{E}, \mathrm{F}$ : Postoperatively, the major thoracic Cobb angle was 18 degrees with correction rate of $76.9 \%$. Lumbar curve was 10 degrees. The thoracic kyphosis was 38 degrees. Both SVA and CVA were 0mm. G, H: At 26-month-follow-up, correction maintained well. 